\title{
What are the key determinants of maintenance performance?
}

\author{
Soroush Avakh Darestania* (D), Mandana Ganji ${ }^{\mathrm{b}}$ (D), Rana Imannezhad ${ }^{\mathrm{b}}$ \\ a School of Strategy and Leadership, Faculty of Business and Law, Coventry University, Coventry, UK \\ ${ }^{\mathrm{b}}$ Department of Industrial Engineering, Bandar e Anzali International Branch, lslamic Azad University, Bandar e Anzali, Iran \\ *ad5710@coventry.ac.uk
}

\begin{abstract}
Paper aims: The main objective of the research is to present a combination of fuzzy decision-making techniques to measure the performance of preventive maintenance systems.

Originality: This research is a timely response to studying the prominent role of preventive maintenance performance in reducing cost, profitability, and overall organization's output.

Research method: This study considers the application of "fuzzy DEMATEL" and ANP techniques for measuring maintenance performance and determining the causal relationships between the criteria and sub-criteria.

Main findings: It is conjectured that functional and technical criteria, along that with individual and the environmental are of great importance. Among the sub-criteria, employee satisfaction, growth and learning, availability of machinery and equipment, quality of maintenance by the skilled and highly-trained workforce, deem to be the most important ones.

Implications for theory and practice: The application of the decision techniques and the proposed measurement model for continuous improvement and promotion of maintenance performance.

Keywords

Maintenance, PM Performance Measurement, Fuzzy DEMATEL Technique, Fuzzy Network Analysis (ANP), Multi-criteria Decision Making
\end{abstract}

How to cite this article: Darestani, S. A., Ganji, M., \& Imannezhad, R. (2020). What are the key determinants of maintenance performance? Production, 30, e20190155. https://doi.org/10.1590/0103-6513.20190155

Received: Jan. 14, 2020; Accepted: Aug. 5, 2020.

\section{Introduction}

Today, with the advancement of technology and the increasing use of machinery in manufacturing industries, investors and managers consider different ways to decrease sudden machinery failure and to increase their useful life, aiming to gain the highest possible performance from the equipment at the lowest cost (Can Özcan et al., 2017). Maintenance, as a useful and important tool in various fields, helps manufacturing companies to have an active presence in the competitive manufacturing markets, (Gandhare \& Akarte, 2012). The present study aims to identify the dimensions and criteria of maintenance and repair performance in the automotive industry and determine the importance of the dimensions and criteria of maintenance and repair performance using multi-criteria decision-making techniques. Two types of questionnaires were used in this study in order to collect data: DEMATEL Technique questionnaire to determine causal relationships between criteria and sub-criteria, and pairwise comparison matrix questionnaire to perform calculations of network analysis process and evaluating the status of each criterion in Iran Khodro Company. The Analytical Network Process helps to better illustrate the complexities of the real world. The Analytical Network Process has the advantage that it makes it possible to consider different relationships between decision factors (i.e., relationships between criteria or the effect of decision alternatives on criteria or relationships between decision alternatives). The present study is an 
applied-developmental research in terms of the purpose and a descriptive research in terms of the data collection approach. The purposeful sampling of judgmental type was also used in this study as the sampling approach. The main objective of this study is to present a combination of fuzzy DEMATEL technique and fuzzy network analysis process to determine the relationships between some case-dependent selective criteria and sub-criteria, and to determine their relative importance particularly in the company under study, namely Iran Khodro. Research questions are: what are the important and influential dimensions in the measurement of preventive maintenance performance in Iran Khodro Company? What is the significance of the identified dimensions? What solutions can be offered to improve preventive maintenance performance in Iran Khodro Company?

In this context, we review the theoretical basics of the research literature first, then we will address the proposed hybrid MCDM model and research method, and finally we present data analysis along with conclusions and future directions of research.

\section{Literature review}

So far, different strategies have been proposed for maintenance, each of which has its own advantages and disadvantages (Jain et al., 2013). First, we define the applied terms in this work. Maintenance process includes all the plans, activities, and operations performed under an acceptable standard operating procedure (SOP) to preserve, control, and increase the useful life of machinery, equipment, installations, and structures in suitable conditions or change them to suitable conditions to be present in the operating cycle. The desirable result of these measures is to preserve the preparedness, operational capability, and the operational continuity of the equipment for predefined conditions (Raufi, 2009).

\subsection{Maintenance and repair strategies}

Corrective maintenance (CM): request for repair works, which are commonly sent by the production personnel to the maintenance unit, is categorized as corrective or routine maintenance, although it may not have the same special priority and conditions as emergency maintenance (Haj Shirmohammadi, 1998).

Preventive maintenance (PM) is the best and usually, the most economical form of maintenance, which is defined, designed, and implemented in a programmed manner based on the objectives and functional or calendar courses (Separi \& Asadi Kiapey, 2012).

Predictive maintenance and condition-based maintenance (CBM): Condition-based maintenance is one type of preventive maintenance where the equipment's condition is monitored (Tsang, 2002). An ideal scenario in maintenance is that it is possible to predict a fault before it occurs, which helps managers to take the necessary measures and change the faulty part before a failure occurs and stops production or operation (Haj Shirmohammadi, 1998). Predictive maintenance involves the use of modern measurement and signal processing methods to accurately predict and diagnose equipment condition during operation (Murthy et al., 2002).

Reliability-centered maintenance (RCM): This process determines the needs for equipment and machinery maintenance under working conditions, to ensure that each equipment can perform its main tasks effectively. The lack of RCM reduces maintenance reliability and efficiency (Noori, 2004).

Total productive maintenance (TPM) is a unique intellectual framework, based on which a comprehensive maintenance system can be developed in an organization. On the other hand, total productive maintenance is considered as one of the main methods in the area of maintenance, which considers the division of operational works among various departments and prevents the concentration of operations at one department (Gandhare \& Akarte, 2012).

TPM is defined as a management approach to maintenance that imports total quality management (TQM) philosophy and techniques to maintenance. TPM focuses on involving all employees in the organization in equipment improvement. (Duffuaa \& Raouf, 2015).

\subsection{Research background in the field of maintenance and repairs}

Fekri Sari \& Avakh Darestani (2019) studied Fuzzy neural networks for evaluating overall equipment effectiveness and line performance measurement. The purpose of this paper was to evaluate well-known production criteria by focusing on Overall Equipment Effectiveness (OEE) and Overall Line Effectiveness (OLE) using the intelligent systems paradigm. They showed that their proposed metrics have been reduced by reducing 
some of the weaknesses of the OEE and OLE methods by using intelligent system techniques such as FIS (Fuzzy Inference Systems) and ANN (Artificial Neural Networks).

Sari et al. (2015) developed a framework for measuring sustainable maintenance performance in the automotive industry. Their proposed framework was presented at three levels of corporate, tactical and operational. Criteria to be considered for measuring performance were also addressed. In the initial framework prepared for measuring sustainable maintenance performance (SMP), 15 measures at the corporate level, 20 measures at the tactical level and 43 measures at the functional level have been identified. Consequently, the level of importance of these measures is investigated through a pilot study in Malaysian car companies. As all measures proposed for measuring SMP are important in automotive companies, 78 proposed measures are classified into three hierarchies among them, eight measures are appropriate. The authors believe that these measures will be useful for automotive companies to develop the SMP measurement system.

Maletič et al. (2014) studied the relationship between quality management orientation and maintenance performance. The experimental data were gathered from a sample of Slovenian organizations.Data were analyzed using exploratory factor, correlation, and regression analyses methods. The results showed that quality management orientation has a significant role on maintenance performance. According to the results of data analysis, the dimensions of quality management orientation are positively correlated with maintenance performance.

Brah \& Chong (2004) examined the relationship between total productive maintenance and organization performance. Their goal is to gain insight into the success factors of a TPM program and to examine the factors of successful TPM implementation to better understand the implementation process. Their results showed a positive and significant relationship between total productive maintenance and business performance (managerial performance, operational performance, and financial performance).

\section{2-3. research background of utilizing MCDM methods}

Using AHP and ANP algorithms, Zaim et al. (2012) conducted a study on the maintenance strategy selection in a case study at a local newspaper-printing center, aiming to illustrate the most appropriate maintenance strategy by using two decision-making methods for organizations having important production requirements. In this research, they considered three corrective, periodic (time-based), and predictive (condition-based) maintenance policies and then, determined the weights of all three different maintenance policies. The results indicated that the two methods were effective for selecting the maintenance strategy and had almost identical results, and predictive maintenance was the most appropriate maintenance strategy in both AHP and ANP analysis.

In another study, Hemmati et al. (2018) evaluated selecting a maintenance strategy for seven devices in a case study at a sulfuric acid manufacturing company, aiming to develop a fuzzy analytic network process model to select the best maintenance strategy. For this purpose, they investigated four corrective maintenance (CM), time-based maintenance (TBM), condition-based maintenance (CBM), and Shutdown maintenance (SM). Based on the results, the CBM policy is suitable for high-risk equipment (cooling tower) and high value-added equipment (absorption tower). Also, TBM is selected for boilers and converters while SM is used for molten sulfur pools. Finally, the corrective maintenance (CM) policy was utilized for low cost, low risk, and low-value equipment (sulfur fuel furnace and heat exchanger), due to its suitability in the process.

Rouyendegh et al. (2018) developed an integrated ANP and fuzzy intuitive TOPSIS model for the supplier selection. This study uses an ANP-IFT-based assessment method in which, uncertainty and subjectivity are considered with linguistic values. First, the supplier selection problem is formulated using ANP, and then the weight of the criteria is determined by considering the effect of interference between the selection criteria. According to the results of this study, group decision making is a useful method for alternative choices. Also, the ANP-IFT hybrid model has the ability to deal with similar types of similar situations with uncertainty in MCDM problems.

Abdulgader et al. (2018) developed a decision support model using a fuzzy MCDM method to select a maintenance program. The research model is designed to include three methods of FAHP, FDEMATEL and FTOPSIS, in a complete decision model. Six different maintenance strategies were developed for this purpose. In this research, the model of the maintenance strategy selection program was used. Finally, the main criteria and sub-criteria were identified to use the F-AHP and F-DEMATEL parts of the model.

To select the concept of urban procurement, a combined MCDM model based on fuzzy DEMATEL, fuzzy ANP and fuzzy VIKOR has been developed in the study of Tadić et al. (2014). The proposed assessment model was implemented to select the concept of Crowd Logistics (CL) in Belgrade as the administrative and economic capital of the Republic of Serbia. 
In a study to select the concept of agility, Vinodh et al. (2016) used fuzzy DEMATEL, fuzzy ANP and fuzzy TOPSIS. They studied an Indian car plastic parts manufacturing organization operating in Bangalore, India with their proposed model. Their goal was to select the best concept design for a car component, and finally, implementing the design chosen by the organization. In their 2017 study, Khompatraporn \& Somboonwiwat (2017) identified the factors affecting the car supply chain competition in Thailand using the fuzzy DEMATEL method. Their proposed method forms a structural model that classifies cause and effect roles.

Maintenance managers need maintenance performance information to monitor and control maintenance processes and their results, therefore they can take steps to improve maintenance performance. In the pertinent literature, maintenance performance is considered as a critical component of corporate success and competitiveness. Therefore, the maintenance performance is very important for the sustainable performance of a manufacturing plant (Muchiri et al., 2010).

The present study aims to identify the dimensions and criteria of maintenance and repair performance in the automotive industry and determine the importance of the dimensions and criteria of maintenance and repair performance using multi-criteria decision-making techniques. Therefore, data were collected from Iran Khodro Company according to the research methodological considerations. Maintenance performance is considered as a vital component of a company's success and competitiveness. As an important industry, many industries are dependent on the automotive industry. These industries are divided into two categories: upstream and downstream industries. The upstream industries includes industries such as steel, metals, mining, rubber, plastic, glass and electronics, and the downstream industries include after-sales service, insurance, leasing, transportation, media and advertising, repair centers, etc. Iran's automotive industry includes production, supply, and after-sales service, which are provided by authorized agents. As the first and most important Iranian car company, the company's activities include providing after-sales services to all Iran Khodro products and its subsidiaries, preparing and distributing, purchase and selling, exporting and importing parts and spare parts for all types of cars and their after-sales services, conducting commercial and non-commercial transactions, and any authorized profitable operation.

As the literature review shows, most maintenance studies have evaluated and selected the most appropriate and optimal maintenance strategies, with no or little consideration being given to measuring maintenance performance. As far as we know, no comprehensive and accepted conceptual model is presented in the field of maintenance and repair, and various authors and researchers have used different criteria and indicators depending on the field of research.

A comprehensive model for maintenance performance was not found in the literature to the best of our knowledge. Overall, the measurement of the maintenance performance, determining the causal relationships between the criteria and sub-criteria, and determining their relative importance together as an innovative way to solve the problem have not been addressed in the literature by far. Therefore, considering the important and prominent role of maintenance performance in cost reduction, profitability and overall performance of the organization, measurement of maintenance performance as an important gap of this research is addressed. This study also considers both the application and combination of two fuzzy DEMATEL techniques and the fuzzy network analysis process.

\section{The proposed hybrid MCDM model}

The research can be categorized as a descriptive-analytical method. The present study measures the maintenance performance of Iran Khodro Company. The statistical population of the research comprises of all the staff and experts of the company who are able to assist us in conducting the research by presenting their opinions. Multi-criteria decision making as a scientific approach was utilized. This helps the decision maker identify, describe and evaluate options to rank, group or select them(Yang et al., 2006).

Various methods can be used to determine criteria weights and prioritize alternatives such as Eigen vector Methods, weighted least squares method, Shannon entropy, hierarchical process and Linmap. The network analysis process and DEMATEL are two of the recently-developed multi-criteria decision making techniques that is gaining attention (Lin et al., 2009). We adopted a variation of this techniques in the present study.

In this study, a purposeful and judgmental sampling is used via introducing a questionnaire. In order to complete this questionnaire and to perform calculations using fuzzy DEMATEL techniques and fuzzy network analysis process, the opinions of 14 experts at the Iran Khodro Company were collected. This method transforms the causal relationship between indicators used under the decision making algorithm into a tangible structural model, where extracting the relationships of influence and mutual impact of available elements in the graph can be achieved by applying the principles of the graph theory. 
The possibility of incorporating relationship feedback is one of the advantages of this approach over existing decision-making methods. Within the proposed structure, each element can affect all of other elements at any hierarchical level. The model dimensions presented by (Sari et al., 2015) to evaluate the performance of maintenance in the automotive industry in Malaysia have been accepted as the benchmark research model in order to select appropriate indicators to measure the performance of maintenance in the automotive industry and also other proposed dimensions that have been used repeatedly in other studies are added to the model. This model was utilized in our study as well.

After finalizing the dimensions and performance measurement indices of maintenance, the Fuzzy DEMATEL method questionnaire was employed. After determining the relationships between criteria and sub-criteria, via the exports opinions through the proposed questionnaire, calculations were performed using the fuzzy network analysis process to establish inter-relationships on attributes associated with each criterion. The steps required to perform the calculations in the DEMATEL method are presented below.

Step 1 - Determine criteria for evaluating and developing a linguistic scale.

The use of linguistic variables and their mathematical formulation is one of the strengths of fuzzy logic.

Step 2 - Obtain decision makers' opinions and calculate the mean using the following equations:

$$
\begin{gathered}
K . \tilde{N}=(k l, k m, k u) \\
\tilde{N}_{l}+\tilde{N}_{2}=l_{l}+l_{2}, m_{l}+m_{2}, u_{l}+u_{2} \\
\tilde{Z}=\frac{\tilde{Z}^{1}+\tilde{Z}^{2}+\ldots+\tilde{Z}^{p}}{P}
\end{gathered}
$$

The fuzzy $\tilde{Z}$ matrix, is called the initial direct-relation matrix.

Step 3 - Calculate the normalized direct-relation matrix using the following equation that the normalized matrix is represented by $\tilde{X}$.

$$
\begin{gathered}
\tilde{X}=\left[\begin{array}{cccc}
\tilde{X}_{11} & \tilde{X}_{12} & \ldots & \tilde{X}_{1 n} \\
\tilde{X}_{21} & \tilde{X}_{22} & \ldots & \tilde{X}_{2 n} \\
\vdots & \vdots & \ddots & \vdots \\
\tilde{X}_{n 1} & \tilde{X}_{n 2} & \ldots & \tilde{X}_{n m}
\end{array}\right] \\
\tilde{X}_{i j}=\frac{\tilde{Z}_{i j}}{r}=\left(\frac{l_{i j}}{r}, \frac{m_{i j}}{r}, \frac{u_{i j}}{r}\right) \\
\tilde{a}_{i}=\sum_{j=1}^{n} \tilde{Z}_{i j}=\sum_{j=1}^{n} l_{i j}, \sum_{j=1}^{n} m_{i j}, \sum_{j=1}^{n} u_{i j} \\
r=\max _{1 \leq i \leq n}\left(\sum_{j=1}^{n} u_{i j}\right.
\end{gathered}
$$

Step 4 - Calculate the total influence matrix using the following equations, the total influence matrix is represented by $\tilde{T}$.

$$
\begin{gathered}
\tilde{T}=\lim _{K \rightarrow \infty}\left(\tilde{X}^{1}+\tilde{X}^{2}+\ldots+\tilde{X}^{K}\right) \\
\tilde{T}=\left[\begin{array}{cccc}
\tilde{t}_{11} & \tilde{t}_{12} & \ldots & \tilde{t}_{1 n} \\
\tilde{t}_{21} & \tilde{t}_{22} & \ldots & \tilde{t}_{2 n} \\
\vdots & \vdots & \ddots & \vdots \\
\tilde{t}_{n 1} & \tilde{t}_{n 2} & \ldots & \tilde{t}_{n m}
\end{array}\right]
\end{gathered}
$$




$$
\begin{gathered}
\tilde{t}_{i j}=\left(l_{i j}^{n}, m_{i j}^{n}, u_{i j}^{n}\right) \\
l_{i j}^{n}=X_{l} \times\left(I-X_{l}\right)^{-1} \\
m_{i j}^{n}=X_{m} \times\left(I-X_{m}\right)^{-1} \\
u_{i j}^{n}=X_{u} \times\left(I-X_{u}\right)^{-l}
\end{gathered}
$$

We can now calculate $\tilde{D}_{i}+\tilde{R}_{i}$ and $\tilde{D}_{i}-\tilde{R}_{i}$. Where $\tilde{D}_{i}$ and $\tilde{R}_{i}$ denotes the sum of rows and columns in matrix T, respectively. BNP method is used for non-fuzzy performance based on the following equations.

$$
B N P=1+\frac{(u-l)+(m-l)}{3}
$$

The cause and effect relationship-graph is also drawn using the T matrix.

Fuzzy decision making is the generalized mode of classical decision-making. The optimal decision in classical decision-making is made from among the possible decisions in the face of the constraints of the problem and with the aim of optimizing the utility function. The utility function, parameters and constraints of the problem are assumed to be accurate in classical decision making, while $\mathrm{x}$ it is possible in classical decision-making to define parameters, utility function, and problem constraints indefinitely and approximately (Saaty, 1996). The Fuzzy Analytical Network Process aims to eliminate uncertainty and fuzziness or doubt in evaluations, especially in the initial stages. Because of the skepticism and complexity of the situation and also, of the inherent nature of human judgments, it seems unrealistic and impossible to obtain accurate judgments for pairwise comparisons in some cases. Making linguistic judgments in assessments that depend on one's way of thinking seems easy and logical. Therefore, we have to accept some of the reasons for the ambiguity in the complex decisions of real numbers, which can be solved by the theory of fuzzy sets. Furthermore, fuzzy-based techniques can be used as a generalized form of analysis that generates uncertain and ambiguous information. The use of analytical network method requires sufficient knowledge of the decision-making goal and the decision environment and all decision-making elements by the decision maker.

In the process of network analysis, it is possible to identify and classify relationships between different components of the decision making process that are under the same criteria, sub-criteria, and decision options. In fact, when solving a multi-criteria decision problem by the network analysis process, the decision maker needs the network as well as the super-matrix. The process of solving the fuzzy network analysis decision model used in this study consists of 4 steps as presented below:

Step 1 - Forming the network.

The desired network is formed according to the refined criteria and sub-criteria of measuring maintenance and repair performance.

Step 2- Determine the relationships between elements of the decision network.

Step 3 - Perform fuzzy-paired comparisons to obtain the super-matrix.

Preparations for the formation of supermatrix should be prepared according to the decision network. At this stage, three types of pairwise comparisons are performed:

A) Performing fuzzy pairwise comparisons and calculating the weight of criteria and sub-criteria without considering dependence:

In this section, the pairwise comparisons matrices are formed without considering the dependence between the decision factors and are provided to the experts. A geometric mean is used in order to combine the results.

B) Perform pairwise comparisons to calculate weights related to internal relationships and dependencies: 
In this section, the internal relationships of criteria and sub-criteria are considered and pairwise comparison matrices are formed. Then, calculations are made using the opinions of experts.

C) Performing pairwise comparisons between decision alternatives

Supermatrix is formed by columns, each of which is a special vector of a block and is represented by w.

We use the notion of a Super Matrix that is a segmented matrix containing the computation results of all previous steps. There are various methods for performing calculations in fuzzy network analysis process that in this study, Chang's extent analysis method is used. The Necessary steps to perform the calculation in the Chang method are presented below.

1- Calculate the value of $S_{k}$ for each of the matrix rows of the pairwise comparisons. Note that

$$
S_{k}=\sum_{j=1}^{n} M_{i j} \times\left[\sum_{i=1}^{m} \sum_{j=1}^{n} M_{i j}\right]^{-1}
$$

$\mathrm{k}$ denotes rows, and $\mathrm{i}$ and $\mathrm{j}$ represent alternatives and indicators, respectively.

2. Calculate the degree of Magnification,

Thus, for instance, if $M_{1}$ and $M_{2}$ are two triangular fuzzy number, the magnitude of $M_{1}$ and $M_{2}$ is defined as follows:

$$
\begin{gathered}
\left\{\begin{array}{l}
V\left(M_{1} \geq M_{2}\right)=1 \quad \text { if }\left(m_{1} \geq m_{2}\right. \\
V\left(M_{1}<M_{2}\right)=\operatorname{hgt}\left(M_{1} \cap M_{2}\right) \quad \text { otherwise }
\end{array}\right. \\
\operatorname{hgt}\left(M_{1} \cap M_{2}\right)=\frac{U_{1}-L_{2}}{\left(U_{1}-L_{2}\right)+\left(m_{2}-m_{1}\right)}
\end{gathered}
$$

The magnitude of one triangular fuzzy number from $K$ to the other triangular fuzzy number is obtained from the following equation.

$$
V\left(M_{1} \geq M_{2}, \ldots, M_{k}\right)=V\left(M_{1} \geq M_{2}\right) \text { and } \ldots \text { and } V\left(M_{1} \geq M_{k}\right)
$$

\section{Calculating abnormal weights.}

The pairwise comparisons matrix is also used to calculate the weights of the indices as follows.

$$
w\left(x_{i}\right)=\min \left\{V\left(S_{i} \geq S_{k}\right)\right\} \quad K=1,2,3, \ldots, n, k \neq i
$$

Therefore, the weight vector of the indices, which is the vector of abnormal coefficients, will be as follows.

$$
w=\left[w\left(x_{1}\right), w\left(x_{2}\right), \ldots, w\left(x_{n}\right)\right]^{t}
$$

4- Calculating normal weights.

The following steps were conducted to obtain the normal vector. These steps are performed for all tables to obtain their normal weight.

$$
w\left(x_{k}\right)=\frac{w\left(x_{k}\right)}{\sum_{k=1}^{n} \dot{w}\left(x_{k}\right)}
$$

Then, a group decision is calculated using the pairwise comparisons matrix of the following equation.

$$
A_{i j}=\left(\prod_{k=1}^{m} A_{i j}^{w k}\right)^{\frac{1}{\sum w k}}
$$


Sometimes a decision is not made by a particular person, but the consent of several people is needed when making a decision. When the number of decision-makers is more than one, each person can be asked for a pairwise comparison matrix. That is, each person was asked individually, then the above relationship is used to calculate the matrix elements of the pairwise comparisons. In the above equation, $A$ is integrated pairwise comparisons matrix for individual's opinion, and $\dot{A}$ is a matrix of individual opinions, and ${ }^{w_{k}}$ is the weight given to each individual's opinion. In other words, it need to take the weighted geometric mean of the pairwise comparisons matrix of individuals.

\section{Case study and analysis}

The role of the supply chain in achieving competitiveness in various industries, including the automotive industry, has received significant attention in recent years. The automotive industry is one of the key industries as development indicators in countries. Due to the competitive advantages of the automotive industry in lran, Iran Khodro's supply chain includes SAPCO (supply), Iran Khodro (production) and ISACO (after-sales service) companies.

Supply chain has a positive and significant effect on the competitiveness of the organization. Applying a proper maintenance system to an organization can play a huge role in reducing the cost of the finished product. However, these impacts are not limited to the cost and will have their own impacts on the speed of delivery across the entire supply chain, product quality, reliability, organization agility, as well.

In this study, fuzzy DEMATEL technique was used to determine the relationship between the selected criteria and sub-criteria of maintenance performance. For this purpose, the questionnaire (1) was used to collect experts' opinions. The computational steps and procedures and results obtained are presented below.

The final result suggests that the utilization of 4 main criteria and 14 sub-criteria of maintenance performance would yield sufficient data. 14 experts participated in data collection to measure the relationships among the criteria and the average matrix was calculated using the Equations 1-3. Direct normalized influence matrix was then calculated using the Equations 4-7 and the values of $\tilde{X}$ and $r$ were obtained. In the last step, the total influence matrix was calculated using the Equations 8-13. The total influence matrix shows the intensity of the relative effect of the direct and indirect relation existing in the system. The results of this step are shown in Appendix A. For the purpose of defuzzification, the BNP method was employed using the Equation 14 and the resulting matrix is shown in Appendix A.

In order to determine the relationship among the 14 identified sub-criteria, the above computational procedure was repeated. Due to the curse of dimensionality, when dealing with the fuzzy matrices, it is not possible to provide a traceable closed-form computational procedure here. The cause and effect relationships graph of this step, however, is shown in Figure 1.

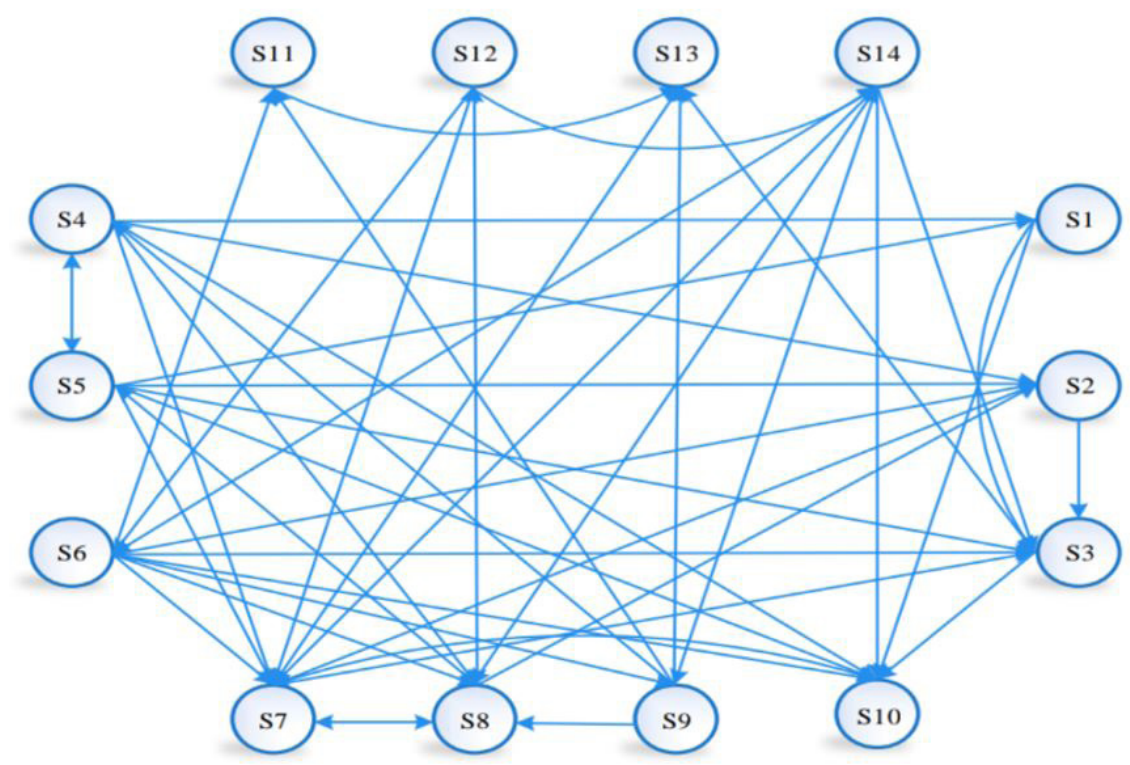

Figure 1. Cause-and-effect relationships Diagram. 
The graph representation of the relationships obtained from these calculations would be difficult to comprehend. For clarity, the relationships obtained in the form of a matrix $(0,1)$ are shown in Table 1.

The network required to apply the analysis process on is drawn according to the criteria and sub-criteria of maintenance performance. The criteria and sub-criteria are shown in Table 2.

From the decision-making network, the formation of the super-matrix was provided. At this step, the pairwise comparison matrix was first formulated without regard to internal relationships and it was made available to experts to evaluate. The geometric mean was used as the metric to integrate the results. Furthermore, calculations were performed based on Chang's analysis method. First, the average matrix was calculated, then, using the presented equations, the sum of fuzzy number row results is computed. In the next step, the value of $S_{k}$ for each of the matrix row of the pairwise comparisons is calculated using Equation 15. After calculating $S_{k}$, the 2-norm magnitude of the $S_{i} s$ relative to the $S_{i} s$ ( $j$ column index and i row index) was calculated using the Equations 16-18. Results are shown in Appendix B.

The abnormal weights obtained using Equations 19 and 20, and the normal weights obtained using the Equations 21 and 22 are shown in Appendix B.

By performing the above-mentioned procedure, the $W_{21}$ and $W_{32}$ vectors were obtained. The $W_{21}$ vector denotes the degree of impact of the objective function on each criterion and the $W_{32}$ vector denotes the impact of the objective function on each of the sub-criteria that are shown in Table 3.

In the next step, the inner-relationship between the criteria and sub-criteria was considered and matrices of paired comparisons were generated considering the information obtained via the experts' opinions. The vectors

Table 1. Sub-criteria relationships

\begin{tabular}{cccccccccccccc}
\hline $\mathrm{S}_{1}$ & $\mathrm{~S}_{2}$ & $\mathrm{~S}_{3}$ & $\mathrm{~S}_{4}$ & $\mathrm{~S}_{5}$ & $\mathrm{~S}_{6}$ & $\mathrm{~S}_{7}$ & $\mathrm{~S}_{8}$ & $\mathrm{~S}_{9}$ & $\mathrm{~S}_{10}$ & $\mathrm{~S}_{11}$ & $\mathrm{~S}_{12}$ & $\mathrm{~S}_{13}$ & $\mathrm{~S}_{14}$ \\
\hline $\mathbf{S}_{1}$ & 0 & 1 & 0 & 0 & 0 & 0 & 0 & 0 & 1 & 0 & 0 & 0 & 0 \\
$\mathbf{S}_{2}$ & 0 & 1 & 0 & 0 & 0 & 0 & 0 & 0 & 1 & 0 & 0 & 0 & 0 \\
$\mathbf{S}_{3}$ & 0 & 0 & 0 & 0 & 0 & 0 & 0 & 0 & 0 & 0 & 0 & 1 & 0 \\
$\mathbf{S}_{4}$ & 1 & 0 & 0 & 1 & 0 & 1 & 1 & 0 & 1 & 0 & 0 & 0 & 0 \\
$\mathbf{S}_{5}$ & 1 & 1 & 1 & 0 & 0 & 1 & 1 & 0 & 1 & 0 & 0 & 0 & 0 \\
$\mathbf{S}_{6}$ & 1 & 1 & 0 & 0 & 0 & 1 & 1 & 1 & 1 & 1 & 0 & 0 & 1 \\
$\mathbf{S}_{7}$ & 1 & 1 & 0 & 0 & 0 & 0 & 1 & 0 & 1 & 0 & 0 & 1 & 1 \\
$\mathbf{S}_{8}$ & 1 & 0 & 0 & 1 & 0 & 1 & 0 & 0 & 0 & 1 & 1 & 0 & 0 \\
$\mathbf{S}_{9}$ & 0 & 0 & 1 & 0 & 0 & 0 & 1 & 0 & 0 & 1 & 0 & 1 & 0 \\
$\mathbf{S}_{10}$ & 0 & 0 & 0 & 0 & 0 & 1 & 0 & 0 & 0 & 0 & 0 & 0 & 0 \\
$\mathbf{S}_{11}$ & 0 & 0 & 0 & 0 & 0 & 0 & 0 & 0 & 0 & 0 & 1 & 0 & 0 \\
$\mathbf{S}_{12}$ & 0 & 0 & 0 & 0 & 1 & 1 & 1 & 0 & 0 & 0 & 0 & 0 \\
$\mathbf{S}_{13}$ & 0 & 0 & 0 & 0 & 0 & 1 & 0 & 0 & 0 & 0 & 0 & 0 & 0 \\
$\mathbf{S}_{14}$ & 0 & 1 & 0 & 0 & 1 & 1 & 1 & 1 & 1 & 0 & 1 & 0 & 0 \\
\hline
\end{tabular}

Table 2. Criteria and sub-criteria of maintenance performance measurement

\begin{tabular}{|c|c|c|c|c|}
\hline Authors & Criterion & Abbreviation & Sub-criteria & Abbreviation \\
\hline Amrina et al. (2019) & \multirow{3}{*}{ Economic } & \multirow{3}{*}{$C_{1}$} & Maintenance cost & $\mathrm{S}_{1}$ \\
\hline \multirow[t]{3}{*}{ Sari et al. (2015) } & & & Breakdown Cost & $\mathrm{S}_{2}$ \\
\hline & & & Maintenance Value & $\mathrm{S}_{3}$ \\
\hline & \multirow{3}{*}{ Support } & \multirow{3}{*}{$\mathrm{C}_{2}$} & Spare Parts Inventory & $\mathrm{S}_{4}$ \\
\hline \multirow[t]{3}{*}{ Cruz \& Haugan (2019) } & & & Logistic & $\mathrm{S}_{5}$ \\
\hline & & & Skilled and Trained Workforce & $\mathrm{S}_{6}$ \\
\hline & \multirow{4}{*}{ Functional } & \multirow{4}{*}{$\mathrm{C}_{3}$} & Quality for Maintenance & $\mathrm{S}_{7}$ \\
\hline \multirow{3}{*}{ Oliveira et al. (2016) } & & & Availability & $\mathrm{S}_{8}$ \\
\hline & & & Reliability & $\mathrm{S}_{9}$ \\
\hline & & & Productivity & $\mathrm{S}_{10}$ \\
\hline \multirow{4}{*}{$\begin{array}{l}\text { Amrina et al. (2019) } \\
\text { Sari et al. (2015) }\end{array}$} & \multirow{4}{*}{ Social \& People } & \multirow{4}{*}{$\mathrm{C}_{4}$} & Safety / Risk/ Health & $\mathrm{S}_{11}$ \\
\hline & & & Employee Satisfaction & $\mathrm{S}_{12}$ \\
\hline & & & Stakeholders Satisfaction & $\mathrm{S}_{13}$ \\
\hline & & & Learning and Growth & $\mathrm{S}_{14}$ \\
\hline
\end{tabular}


Table 3. $W_{21}$ vector and $W_{32}$ matrix

\begin{tabular}{|c|c|c|c|c|c|c|}
\hline \multirow{2}{*}{\multicolumn{3}{|c|}{ Weight of criteria relative to objective function $\left(\mathrm{W}_{21}\right)$}} & \multicolumn{4}{|c|}{ Sub-Criteria Weight to Criteria $\left(\mathrm{W}_{33}\right)$} \\
\hline & & & \multirow{2}{*}{$\frac{C_{1}}{0.285}$} & \multirow{2}{*}{$\frac{\mathrm{C}_{2}}{0}$} & \multirow{2}{*}{$\frac{C_{3}}{0}$} & \multirow{2}{*}{$\frac{C_{4}}{0}$} \\
\hline $\mathrm{C}_{1}$ & 0.19 & $\mathrm{~S}_{1}$ & & & & \\
\hline & & $\mathrm{S}_{2}$ & 0.374 & 0 & 0 & 0 \\
\hline & & $\mathrm{S}_{3}$ & 0.341 & 0 & 0 & 0 \\
\hline \multirow[t]{3}{*}{$\mathrm{C}_{2}$} & 0.232 & $\mathrm{~S}_{4}$ & 0 & 0.344 & 0 & 0 \\
\hline & & $\mathrm{S}_{5}$ & 0 & 0.313 & 0 & 0 \\
\hline & & $\mathrm{S}_{6}$ & 0 & 0.344 & 0 & 0 \\
\hline \multirow[t]{4}{*}{$\mathrm{C}_{3}$} & 0.33 & $\mathrm{~S}_{7}$ & 0 & 0 & 0.274 & 0 \\
\hline & & $\mathrm{S}_{8}$ & 0 & 0 & 0.313 & 0 \\
\hline & & $\mathrm{S}_{9}$ & 0 & 0 & 0.206 & 0 \\
\hline & & $\mathrm{S}_{10}$ & 0 & 0 & 0.206 & 0 \\
\hline \multirow[t]{4}{*}{$\mathrm{C}_{4}$} & 0.248 & $S_{11}$ & 0 & 0 & 0 & 0.268 \\
\hline & & $\mathrm{S}_{12}$ & 0 & 0 & 0 & 0.298 \\
\hline & & $\mathrm{S}_{13}$ & 0 & 0 & 0 & 0.217 \\
\hline & & $\mathrm{S}_{14}$ & 0 & 0 & 0 & 0.217 \\
\hline
\end{tabular}

obtained from the pairwise comparisons matrix of criteria internal relations formed $\mathrm{W}_{22}$ matrix, and the special vectors obtained from the pairwise comparisons of the sub-criteria internal relations form the $\mathrm{W}_{33}$ matrix. Zero values in the special vectors belong to independent criteria.

After conducting pairwise comparisons based on internal relationships between criteria, four special vectors were obtained and The $\mathrm{W}_{22}$ matrix was formed that the results are shown in Table 4.

Table 4. Internal relations matrix of criteria

\begin{tabular}{ccccc}
\hline & $\mathrm{C}_{1}$ & $\mathrm{C}_{2}$ & $\mathrm{C}_{3}$ & $\mathrm{C}_{4}$ \\
\hline $\mathrm{C}_{1}$ & 0 & 0 & 0.5 & 0.5 \\
$\mathrm{C}_{2}$ & 0.43 & 0 & 0.57 & 0 \\
$\mathrm{C}_{3}$ & 0 & 0 & 1 & 0 \\
$\mathrm{C}_{4}$ & 0.451 & 0 & 0.549 & 0 \\
\hline
\end{tabular}

The $\mathrm{W}_{33}$ matrix is presented in Table 5 which shows the weighted vectors obtained from the pairwise comparisons matrices related to the internal relationships of the sub-criteria.

In the next step, we formed and solved the super matrix. Super matrix was a segmented matrix that holds the calculation results of that in all previous steps. In other words, the vectors and matrices obtained from the previous steps were categorized and incorporated into the super matrix according to some general rules. In fact, this super matrix is used to calculate the weight of all selected sub-criteria. After obtaining the un-weighted super matrix, some of the columns in the obtained matrix may not be possible columns or simply the sum of the column elements may not turn to be one, in which case, it cannot be said that the ultimate impact of the control criterion on all the elements is properly represented.

It is noteworthy that one should use the results obtained within the comparison of categories, by multiplying the normalized values corresponding to each criterion to their effect and normalizing to achieve the final convergence of the columns. In order to achieve the convergence of the importance of weights, the weighted super matrix was subjected to a power law of $2 k+1$, where $k$ was normally selected as a large number. The obtained super matrix is called a "limited super matrix and the results are shown in Table 6. The weighted super matrix converged with 15 replications in this study. Given this super matrix, the weight and importance of each sub-criterion can be extracted.

The fuzzy network analysis process calculations were performed to determine the importance and priority of the dimensions of the maintenance performance measurement framework. The results are shown in Table 7 and Figure 2.

As can be seen in Table 7, among selected criteria, the functional and technical criteria and the individuals and the environment were of much greater importance than the other two criteria for measuring the performance of maintenance and the relative importance and weight of the criteria and sub-criteria is shown in Figure 2. 
Table 5. Internal relations matrix of sub-criteria

\begin{tabular}{ccccccccccccccc}
\hline & $\mathrm{S}_{1}$ & $\mathrm{~S}_{2}$ & $\mathrm{~S}_{3}$ & $\mathrm{~S}_{4}$ & $\mathrm{~S}_{5}$ & $\mathrm{~S}_{6}$ & $\mathrm{~S}_{7}$ & $\mathrm{~S}_{8}$ & $\mathrm{~S}_{9}$ & $\mathrm{~S}_{10}$ & $\mathrm{~S}_{11}$ & $\mathrm{~S}_{12}$ & $\mathrm{~S}_{13}$ & $\mathrm{~S}_{14}$ \\
\hline $\mathrm{S}_{1}$ & 0 & 0 & 0.5 & 0 & 0 & 0 & 0 & 0 & 0 & 0.5 & 0 & 0 & 0 & 0 \\
$\mathrm{~S}_{2}$ & 0 & 0 & 0.5 & 0 & 0 & 0 & 0 & 0 & 0 & 0.5 & 0 & 0 & 0 & 0 \\
$\mathrm{~S}_{3}$ & 0 & 0 & 0 & 0 & 0 & 0 & 0 & 0 & 0 & 0 & 0 & 0 & 1 & 0 \\
$\mathrm{~S}_{4}$ & 0.167 & 0.167 & 0 & 0 & 0.167 & 0 & 0.167 & 0.167 & 0 & 0.167 & 0 & 0 & 0 & 0 \\
$\mathrm{~S}_{5}$ & 0.114 & 0.114 & 0.114 & 0.167 & 0 & 0 & 0.134 & 0.135 & 0 & 0.144 & 0 & 0 & 0 & 0 \\
$\mathrm{~S}_{6}$ & 0 & 0.122 & 0.122 & 0 & 0 & 0 & 0.122 & 0.148 & 0.118 & 0.118 & 0.125 & 0 & 0 & 0.125 \\
$\mathrm{~S}_{7}$ & 0 & 0.167 & 0.163 & 0 & 0 & 0 & 0 & 0.156 & 0 & 0.203 & 0 & 0 & 0.154 & 0.156 \\
$\mathrm{~S}_{8}$ & 0 & 0.25 & 0 & 0 & 0.242 & 0 & 0.254 & 0 & 0 & 0 & 0 & 0.254 & 0 & 0 \\
$\mathrm{~S}_{9}$ & 0 & 0 & 0 & 0.212 & 0 & 0 & 0 & 0.318 & 0 & 0 & 0.235 & 0 & 0.235 & 0 \\
$\mathrm{~S}_{10}$ & 0 & 0 & 0 & 0 & 0 & 0 & 1 & 0 & 0 & 0 & 0 & 0 & 0 & 0 \\
$\mathrm{~S}_{11}$ & 0 & 0 & 0 & 0 & 0 & 0 & 0 & 0 & 0 & 0 & 0 & 0 & 1 \\
$\mathrm{~S}_{12}$ & 0 & 0 & 0 & 0 & 0 & 0.243 & 0.243 & 0.243 & 0 & 0 & 0 & 0 & 0 & 0.271 \\
$\mathrm{~S}_{13}$ & 0 & 0 & 0 & 0 & 0 & 0 & 1 & 0 & 0 & 0 & 0 & 0 & 0 & 0 \\
$\mathrm{~S}_{14}$ & 0 & 0 & 0.126 & 0 & 0 & 0.126 & 0.126 & 0.231 & 0.13 & 0.112 & 0 & 0.147 & 0 & 0 \\
\hline
\end{tabular}

Table 6. Limited Super Matrix

\begin{tabular}{|c|c|c|c|c|c|c|c|c|c|c|c|c|c|c|c|c|c|c|c|}
\hline & G & $C_{1}$ & $\mathrm{C}_{2}$ & $\mathrm{C}_{3}$ & $\mathrm{C}_{4}$ & $\mathrm{~S}_{1}$ & $\mathrm{~S}_{2}$ & $\mathrm{~S}_{3}$ & $\mathrm{~S}_{4}$ & $\mathrm{~S}_{5}$ & $\mathrm{~S}_{6}$ & $\mathrm{~S}_{7}$ & $\mathrm{~S}_{8}$ & $\mathrm{~S}_{9}$ & $\mathrm{~S}_{10}$ & $\mathrm{~S}_{11}$ & $\mathrm{~S}_{12}$ & $\mathrm{~S}_{13}$ & $\mathrm{~S}_{14}$ \\
\hline $\mathrm{G}$ & 0 & 0 & 0 & 0 & 0 & 0 & 0 & 0 & 0 & 0 & 0 & 0 & 0 & 0 & 0 & 0 & 0 & 0 & 0 \\
\hline$C_{1}$ & 0 & 0 & 0 & 0 & 0 & 0 & 0 & 0 & 0 & 0 & 0 & 0 & 0 & 0 & 0 & 0 & 0 & 0 & 0 \\
\hline $\mathrm{C}_{2}$ & 0 & 0 & 0 & 0 & 0 & 0 & 0 & 0 & 0 & 0 & 0 & 0 & 0 & 0 & 0 & 0 & 0 & 0 & 0 \\
\hline$C_{3}$ & 0 & 0 & 0 & 0 & 0 & 0 & 0 & 0 & 0 & 0 & 0 & 0 & 0 & 0 & 0 & 0 & 0 & 0 & 0 \\
\hline$C_{4}$ & 0 & 0 & 0 & 0 & 0 & 0 & 0 & 0 & 0 & 0 & 0 & 0 & 0 & 0 & 0 & 0 & 0 & 0 & 0 \\
\hline $\mathrm{S}_{1}$ & 0.01 & 0.01 & 0.01 & 0.01 & 0.01 & 0.01 & 0.01 & 0.01 & 0.01 & 0.01 & 0.01 & 0.01 & 0.01 & 0.01 & 0.01 & 0.01 & 0.01 & 0.01 & 0.01 \\
\hline $\mathrm{S}_{2}$ & 0.01 & 0.01 & 0.01 & 0.01 & 0.01 & 0.01 & 0.01 & 0.01 & 0.01 & 0.01 & 0.01 & 0.01 & 0.01 & 0.01 & 0.01 & 0.01 & 0.01 & 0.01 & 0.01 \\
\hline $\mathrm{S}_{3}$ & 0.01 & 0.01 & 0.01 & 0.01 & 0.01 & 0.01 & 0.01 & 0.01 & 0.01 & 0.01 & 0.01 & 0.01 & 0.01 & 0.01 & 0.01 & 0.01 & 0.01 & 0.01 & 0.01 \\
\hline $\mathrm{S}_{4}$ & 0.06 & 0.06 & 0.06 & 0.06 & 0.06 & 0.06 & 0.06 & 0.06 & 0.06 & 0.06 & 0.06 & 0.06 & 0.06 & 0.06 & 0.06 & 0.06 & 0.06 & 0.06 & 0.06 \\
\hline $\mathrm{S}_{5}$ & 0.05 & 0.05 & 0.05 & 0.05 & 0.05 & 0.05 & 0.05 & 0.05 & 0.05 & 0.05 & 0.05 & 0.05 & 0.05 & 0.05 & 0.05 & 0.05 & 0.05 & 0.05 & 0.05 \\
\hline $\mathrm{S}_{6}$ & 0.11 & 0.11 & 0.11 & 0.11 & 0.11 & 0.11 & 0.11 & 0.11 & 0.11 & 0.11 & 0.11 & 0.11 & 0.11 & 0.11 & 0.11 & 0.11 & 0.11 & 0.11 & 0.08 \\
\hline $\mathrm{S}_{7}$ & 0.08 & 0.08 & 0.08 & 0.08 & 0.08 & 0.08 & 0.08 & 0.08 & 0.08 & 0.08 & 0.08 & 0.08 & 0.08 & 0.08 & 0.08 & 0.08 & 0.08 & 0.08 & 0.08 \\
\hline $\mathrm{S}_{8}$ & 0.16 & 0.16 & 0.16 & 0.16 & 0.16 & 0.16 & 0.16 & 0.16 & 0.16 & 0.16 & 0.16 & 0.16 & 0.16 & 0.16 & 0.16 & 0.16 & 0.16 & 0.16 & 0.16 \\
\hline $\mathrm{S}_{9}$ & 0.08 & 0.08 & 0.08 & 0.08 & 0.08 & 0.08 & 0.08 & 0.08 & 0.08 & 0.08 & 0.08 & 0.08 & 0.08 & 0.08 & 0.08 & 0.08 & 0.08 & 0.08 & 0.08 \\
\hline $\mathrm{S}_{10}$ & 0.03 & 0.03 & 0.03 & 0.03 & 0.03 & 0.03 & 0.03 & 0.03 & 0.03 & 0.03 & 0.03 & 0.03 & 0.03 & 0.03 & 0.03 & 0.03 & 0.03 & 0.03 & 0.03 \\
\hline $\mathrm{S}_{11}$ & 0.01 & 0.01 & 0.01 & 0.01 & 0.01 & 0.01 & 0.01 & 0.01 & 0.01 & 0.01 & 0.01 & 0.01 & 0.01 & 0.01 & 0.01 & 0.01 & 0.01 & 0.01 & 0.01 \\
\hline $\mathrm{S}_{12}$ & 0.19 & 0.19 & 0.19 & 0.19 & 0.19 & 0.19 & 0.19 & 0.19 & 0.19 & 0.19 & 0.19 & 0.19 & 0.19 & 0.19 & 0.19 & 0.19 & 0.19 & 0.19 & 0.19 \\
\hline $\mathrm{S}_{13}$ & 0.03 & 0.03 & 0.03 & 0.03 & 0.03 & 0.03 & 0.03 & 0.03 & 0.03 & 0.03 & 0.03 & 0.03 & 0.03 & 0.03 & 0.03 & 0.03 & 0.03 & 0.03 & 0.03 \\
\hline $\mathrm{S}_{14}$ & 0.18 & 0.18 & 0.18 & 0.18 & 0.18 & 0.18 & 0.18 & 0.18 & 0.18 & 0.18 & 0.18 & 0.18 & 0.18 & 0.18 & 0.18 & 0.18 & 0.18 & 0.18 & 0.18 \\
\hline
\end{tabular}

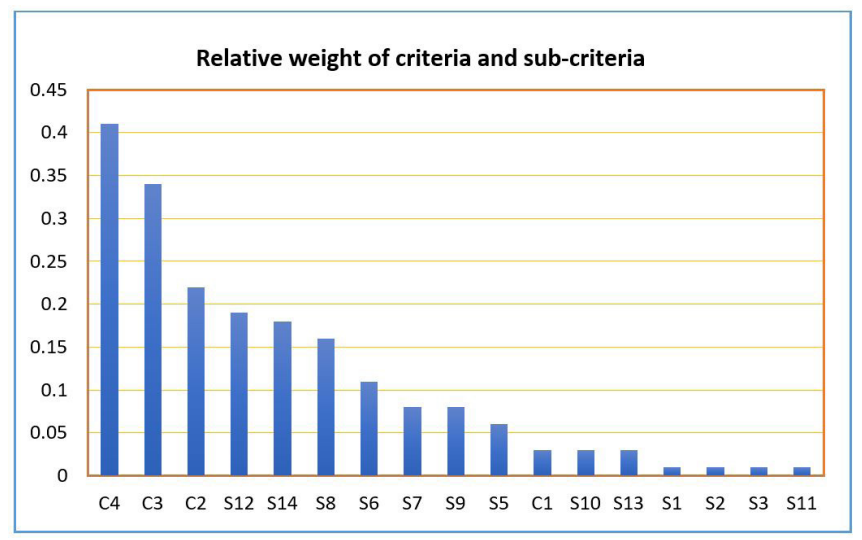

Figure 2. Relative weight of criteria and sub-criteria. 
Table 7. the relative importance and weight of the criteria and sub-criteria

\begin{tabular}{ccccccccc}
\hline & \multicolumn{9}{c}{ weight of the criteria and sub-criteria } \\
\hline $\mathrm{C}_{1}$ & 0.03 & $\mathrm{C}_{2}$ & 0.22 & $\mathrm{C}_{3}$ & 0.34 & $\mathrm{C}_{4}$ & 0.41 \\
$\mathrm{~S}_{1}$ & 0.01 & $\mathrm{~S}_{4}$ & 0.05 & $\mathrm{~S}_{7}$ & 0.08 & $\mathrm{~S}_{11}$ & 0.01 \\
$\mathrm{~S}_{2}$ & 0.01 & $\mathrm{~S}_{5}$ & 0.06 & $\mathrm{~S}_{8}$ & 0.16 & $\mathrm{~S}_{12}$ & 0.19 \\
$\mathrm{~S}_{3}$ & 0.01 & $\mathrm{~S}_{6}$ & 0.11 & $\mathrm{~S}_{9}$ & 0.08 & $\mathrm{~S}_{13}$ & 0.03 \\
& & & $\mathrm{~S}_{10}$ & 0.03 & $\mathrm{~S}_{14}$ & 0.18 \\
\hline
\end{tabular}

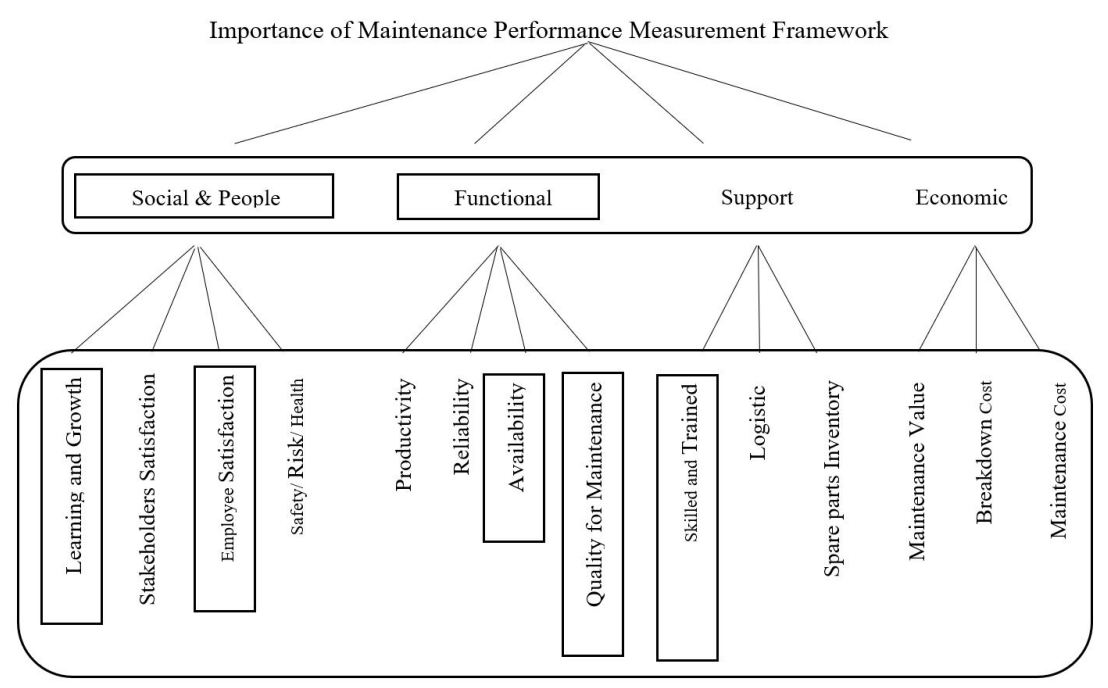

Figure 3. Important factors in measurement of maintenance performance.

Among the selected sub-criteria, employee satisfaction, learning and growth, availability of the machinery and equipment, quality of maintenance and skilled and trained workforce were more important than other sub-criteria. The important information in Table 7 is illustrated on the research tree in Figure 3.

Figure 3 shows which factors are most important to measure maintenance performance.

\section{Conclusion}

Maintenance and repairs performance plays an important role in reducing costs, profitability, and overall organizational performance. Reviewing the previous research, (e.g. Abdulgader et al., 2018), shows the use of the fuzzy hybrid MCDM method to select a maintenance program. Hemmati et al. (2018) presented a fuzzy analytical network process model to select the best repair and maintenance policy. Rouyendegh et al. (2018) used an integrated ANP method and an intuitive fuzzy TOPSIS model to select a supplier. A comprehensive review of existing literature in the field of maintenance performance measurement reveals scarcity in the systematic research in the realm, of modeling maintenance performance. In order to identify and determine the selected criteria and sub-criteria for evaluating the maintenance performance of existing texts, we have proposed to systematically evaluate different views on the dimensions of the maintenance performance measurement framework, first. Muchiri et al. (2010) used performance evaluation indicators in two dimensions: process indicators (job identification, work planning and scheduling, job performance) and result indicators (cost effectiveness, equipment efficiency, safety, and health). Sari et al. (2015) used performance evaluation indicators in three dimensions of economic performance (cost effectiveness, quality, and productivity), social performance (growth and learning, health and safety, employee satisfaction, and stakeholder satisfaction), and environmental performance. On the other hand, a comprehensive review of the pertinent literature revealed that a relatively-wide variation in the dimensions of the maintenance performance measurement framework can be expected. These were categorized into 4 major dimensions using the research (Sari et al., 2015) in the automotive industry and Research (Amrina et al., 2019; Oliveira et al., 2016; Cruz \& Haugan, 2019) and also using experts' opinions. Two types of questionnaires were used in this study to collect the data and information required for the research: DEMATEL technique questionnaire to determine causal relationships between criteria 
and sub-criteria, and pairwise comparison matrix questionnaire to perform calculations of Analytical Network Process and investigating the status of each criterion in Iran Khodro Company. After identifying the criteria and sub-criteria of interest, research questionnaires were developed and data were collected. The view of 14 experts in Iran Khodro Company were used in order to complete the questionnaire and perform calculations using Fuzzy DEMATEL techniques and Fuzzy Analytical Network Process. The data were collected in person and by referring to the research sample. The selection of 14 people as sample experts from 98 experts is due to the fact that a small number of people were able to answer the research questions. The 14 experts were selected among the managers and experts of production lines and managers and maintenance staff who have Bachelor and master degrees and were familiar with repairs and maintenance. Furthermore, the fuzzy DEMATEL technique was used to determine the relationships between criteria and sub-criteria. For this purpose, the questionnaire 1 was distributed among experts (sample) and they were asked to answer the questions carefully according to the scale provided. In this process, 14 questionnaires were collected. Finally, after determining the criteria and sub-criteria, pairwise comparisons questionnaires were prepared and provided to experts in order to measure the performance of maintenance and repairs, as well as the importance of measuring criteria and sub-criteria. Calculations of this stage were performed using Fuzzy Analytical Network process. Finally, the fuzzy network analysis process was used to determine the importance and priority of the dimensions within the maintenance performance measurement framework. The results showed that among the two categories of criteria, the functional and technical, and the individuals and the environment were much more important than the other former ones for measuring maintenance performance. Among the sub-criteria, however, employee satisfaction, growth and learning, availability of machinery and equipment, quality of maintenance and skilled and trained workforce were deemed to be more important than that in other sub-criteria. Since maintenance performs a crucial role in the success and prosperity of organizations, the guidelines provided can guide managers to action in strategic decision making.

Since maintenance performance plays a decisive role in the success of organizations, this paper presents a comprehensive research method of measuring preventive maintenance performance. Results will be useful to researchers, maintenance managers, and other professionals in the relevant industries. The guidelines and techniques presented in this article can be employed by managers for strategic decision making. Based on the results of the research, several strategies can be suggested to improve maintenance performance:

- Since the employee satisfaction sub-criterion has been identified as the most important factor in maintenance performance, managers' greater attention to the issue of employee satisfaction can enhance maintenance performance.

- Growth and learning (including staff training, etc.) is considered as an important sub-criterion. Undoubtedly, providing the environment and conditions that lead to the personal development of the maintenance staff would have practical and tangible benefits for the organization.

According to the research findings, recommendations in line with this research are presented in the form of two categories of practical and research suggestions. Some practical suggestions could be the use of the provided tools and the proposed measurement model for continuous improvement and promotion of maintenance performance. Emphasis on the importance of evaluating the criteria and sub-criteria and adopting strategies to further improve maintenance and repair performance, statistical testing of the proposed framework and examining validation types, and the use of exploratory factor analysis to identify more criteria and sub-criteria are suggested for future studies, Using the proposed framework to evaluate maintenance and repair performance in other sections with adjustments (if necessary). Also, Future research can apply the use of other scientific techniques for ranking criteria and sub-criteria.

\section{References}

Abdulgader, F. S., Eid, R., \& Rouyendegh, B. D. (2018). Development of decision support model for selecting a maintenance plan using a fuzzy mcdm approach - A theoretical framework. Applied Computational Intelligence and Soft Computing, 2018, 1-14. https:// doi.org/10.1155/2018/9346945.

Amrina, E., Yulianto, A., \& Kamil, 1. (2019). Fuzzy multi criteria approach for sustainable maintenance evaluation in rubber industry, 16th Global Conference on Sustainable Manufacturing - Sustainable Manufacturing for Global Circular Economy, Procedia Manufacturing, 33, 538-545. http://dx.doi.org/10.1016/j.promfg.2019.04.067.

Brah, S. A., \& Chong, W. K. (2004). Relationship between total productive maintenance and performance. International Journal of Production Research, 42(12), 2383-2401. http://dx.doi.org/10.1080/00207540410001661418.

Can Özcan, E., Ünlüsoy, S., \& Tamer, E. (2017). A combined goal programming - AHP approach supported with TOPSIS for maintenance strategy selection in hydroelectric power plants. Renewable \& Sustainable Energy Reviews, 78, 1410-1423. http://dx.doi.org/10.1016/j rser.2017.04.039. 
Cruz, A. M., \& Haugan, G. L. (2019). Determinants of maintenance performance: A resource-based view and agency theory approach. Journal of Engineering and Technology Management, 51, 33-47. http://dx.doi.org/10.1016/j.jengtecman.2019.03.001.

Duffuaa, S., \& Raouf, A. (2015). Planning and control of maintenance systems: Modelling and analysis. Berlin: Springer lnternational Publishing. http://dx.doi.org/10.1007/978-3-319-19803-3

Fekri Sari, M., \& Avakh Darestani, S. (2019). Fuzzy overall equipment effectiveness and line performance measurement using artificial neural network. Journal of Quality in Maintenance Engineering, 25(2), 340-354. http://dx.doi.org/10.1108/JQME-12-2017-0085.

Gandhare, B. S., \& Akarte, M. (2012, January 1-4), Maintenance strategy selection. In Ninth AlMS International Conference on Management (pp. 1330-1336). Maharashtra, India: AlMS International.

Haj Shirmohammadi, A. (1998). Total Productive Maintenance (TPM) (1st ed.). Esfahan: Arkan Publications.

Hemmati, N., Rahiminezhad Galankashi, M., Imani, D., \& Farughi, H. (2018), Maintenance policy selection: A Fuzzy-ANP spproach, Journal of Quality in Maintenance Engineering, 29(7), 1253-1268.

Jain, K., Singh Jain, S., \& Singh Chauhan, M. (2013). Selection of optimum maintenance and rehabilitation strategy for multiline highways. IJTTE. International Journal for Traffic and Transport Engineering, 3(3), 269-278. http://dx.doi.org/10.7708/ijtte.2013.3(3).04.

Khompatraporn, C., \& Somboonwiwat, T. (2017). Causal factor relations of supply chain competitiveness via fuzzy DEMATEL method for Thai automotive industry. Production Planning and Control, 28(6-8), 538-551. http://dx.doi.org/10.1080/09537287.2017.1309713.

Lin, C. T., Lee, C., \& Wu, C. S. (2009). Optimizing a marketing expert decision process for the private hotel. Expert Systems with Applications, 36(3), 5613-5619. http://dx.doi.org/10.1016/j.eswa.2008.06.113.

Murthy, D. N. P., Atrens, A., \& Eccleston, J. A. (2002). Strategic Maintenance Management. Journal of Quality in Maintenance Engineering, 8(4), 287-305. http://dx.doi.org/10.1108/13552510210448504.

Muchiri, P. N., Pintelon, L., Martin, H., \& De Meyer, A. M. (2010). Empirical analysis of maintenance performance measurement in Belgian Industries. International Journal of Production Research, 48(20), 5905-5924. http://dx.doi.org/10.1080/00207540903160766.

Maletič, D., Maletič, M., \& Gomišček, B. (2014). The Impact of quality management orientation on maintenance performance. International Journal of Production Research, 52(6), 1744-1754. http://dx.doi.org/10.1080/00207543.2013.848480.

Noori, A. (2004). Reliability-centered maintenance. In 7th Railway Transportation Conference. Tehran, Iran: Sharif University of Technology, Civil Engineering. Retrieved in 2004, April 28, from http://www.civilica.com/Paper-RTC07-RTC07_167.html

Oliveira, M., Lopes, 1., \& Rodrigues, C. (2016). Use of maintenance performance indicators by companies of the industrial hub of Manaus. Procedia CIRP, 52, 157-160. http://dx.doi.org/10.1016/j.procir.2016.07.071.

Raufi, M. (2009), Professional interactions, duties, and activities of maintenance engineering, The First National Conference on Engineering and Management of Infrastructures. Iran: Tehran University.

Rouyendegh, B. D., Topuz K., Dag, A., \& Oztekin, A. (2018), An AHP-IFT Integrated Model for Performance Evaluation of E-commerce Web Sites. Information Systems Journal, 21, 1345-1355. http://dx.doi.org/10.1007/s10796-018-9825-z.

Saaty, T. L. (1996). Decision making with dependence and feedback: The analytic network process (Vol. 4922). Pittsburgh: RWS Publications.

Sari, E., Shaharoun, A. M., Ma'aram, A., \& Yazid, A. M. (2015). Sustainable Maintenance Performance Measures: A pilot survey in Malaysian Automotive Companies. Procedia CIRP, 26, 443-448. http://dx.doi.org/10.1016/j.procir.2014.07.163.

Separi, F., \& Asadi Kiapey, M. B. (2012), Reliability-centered maintenance strategy based on the AHP in distribution networks, 25th International Power System Conference. Teerã: Tavanir Company, Niroo Research Institute. https://www.civilica.com/Paper-PSC25PSC25_262.html.

Tsang, A. H. C. (2002). Strategic dimensions of maintenance management. Journal of Quality in Maintenance Engineering, 8(1), 7-39. http://dx.doi.org/10.1108/13552510210420577.

Tadić, S., Zečević, S., \& Krstić, M. (2014). A novel hybrid MCDM model based on fuzzy DEMATEL, fuzzy ANP and fuzzy VIKOR for city logistics concept selection. Expert Systems with Applications, 41(18), 8112-8128. http://dx.doi.org/10.1016/j.eswa.2014.07.021.

Vinodh, S., Sai Balagi, T. S., \& Patil, A. (2016). A hybrid MCDM approach for agile concept selection using fuzzy DEMATEL, fuzzy ANP and fuzzy TOPSIS. International Journal of Advanced Manufacturing Technology, 83(9-12), 1979-1987. http://dx.doi.org/10.1007/ s00170-015-7718-6.

Yang, J. B., Wang, Y. M., Xu, D. L., \& Chin, K. S. (2006). The Evidential Reasoning Approach for MADA under both Probabilistic and Fuzzy Uncertainties. European Journal of Operational Research, 171(1), 309-343. http://dx.doi.org/10.1016/j.ejor.2004.09.017.

Zaim, S., Turkyılmaz, A., Acar, F., Al-Turki, U., \& Demirel, O. F. (2012). Maintenance strategy selection using AHP and ANP algorithms: A case study. Journal of Quality in Maintenance Engineering, 18(1), 16-29. http://dx.doi.org/10.1108/13552511211226166. 
Appendix A. the fuzzy DEMATEL technique calculations.

Table of total influence matrix

\begin{tabular}{ccccc}
\hline & C1 & C2 & C3 & C4 \\
\hline C1 & $(0.12,0.55,5.33)$ & $(0.07,0.38,3.67)$ & $(0.27,0.75,5.57)$ & $(0.26,0.69,5.06)$ \\
C2 & $(0.31,0.81,5.36)$ & $(0.02,0.26,3.32)$ & $(0.32,0.82,5.34)$ & $(0.12,0.58,4.74)$ \\
C3 & $(0.28,0.75,5.30)$ & $(0.02,0.33,3.44)$ & $(0.10,0.50,5.01)$ & $(0.25,0.66,4.79)$ \\
C4 & $(0.26,0.73,5.33)$ & $(0.02,0.32,3.46)$ & $(0.25,0.72,5.30)$ & $(0.10,0.44,4.55)$ \\
\hline
\end{tabular}

The defuzzified total influence matrix

\begin{tabular}{ccccc}
\hline & C1 & C2 & C3 & C4 \\
\hline C1 & $(1.99)$ & $(1.37)$ & $(2.20)$ & $(2.01)$ \\
C2 & $(2.16)$ & $(1.20)$ & $(2.16)$ & $(1.82)$ \\
C3 & $(2.11)$ & $(1.26)$ & $(1.87)$ & $(1.90)$ \\
C4 & $(2.11)$ & $(1.27)$ & $(2.09)$ & $(1.70)$ \\
\hline
\end{tabular}


Appendix B. the fuzzy network analysis process Calculations.

The sum of fuzzy row numbers

\begin{tabular}{lccc}
\hline & L & M & U \\
\hline R1 & 3.148 & 3.539 & 4.298 \\
R2 & 3.22 & 3.841 & 4.473 \\
R3 & 3.989 & 4.765 & 5.413 \\
R4 & 3.429 & 4.065 & 4.489 \\
SR & 13.79 & 16.21 & 19.14 \\
\hline
\end{tabular}

The value of $\mathbf{s}_{\boldsymbol{k}}$ corresponds to each row of matrix

\begin{tabular}{cccc}
\hline S1 & L & M & U \\
\hline S1 & 0.164 & 0.218 & 0.312 \\
S2 & 0.168 & 0.237 & 0.344 \\
S3 & 0.208 & 0.294 & 0.393 \\
S4 & 0.179 & 0.251 & 0.34 \\
\hline
\end{tabular}

Calculating the degree of magnitude

\begin{tabular}{ccccc}
\hline S1 & S1 & S2 & S3 & S4 \\
\hline S1 & 1 & 1 & 1 & 1 \\
S2 & 0.885 & 1 & 1 & 1 \\
S3 & 0.577 & 0.704 & 1 & 0.753 \\
S4 & 0.803 & 0.923 & 1 & 1 \\
\hline
\end{tabular}

\begin{tabular}{cc} 
Abnormal weights \\
\hline \multicolumn{3}{l}{ weigh } \\
\hline W1 & 0.577 \\
W2 & 0.704 \\
W3 & 1 \\
W4 & 0.753 \\
\hline
\end{tabular}

Normal weights

\begin{tabular}{ll}
\hline & weigh \\
\hline W1 & 0.19 \\
W2 & 0.232 \\
W3 & 0.33 \\
W4 & 0.248 \\
\hline
\end{tabular}

